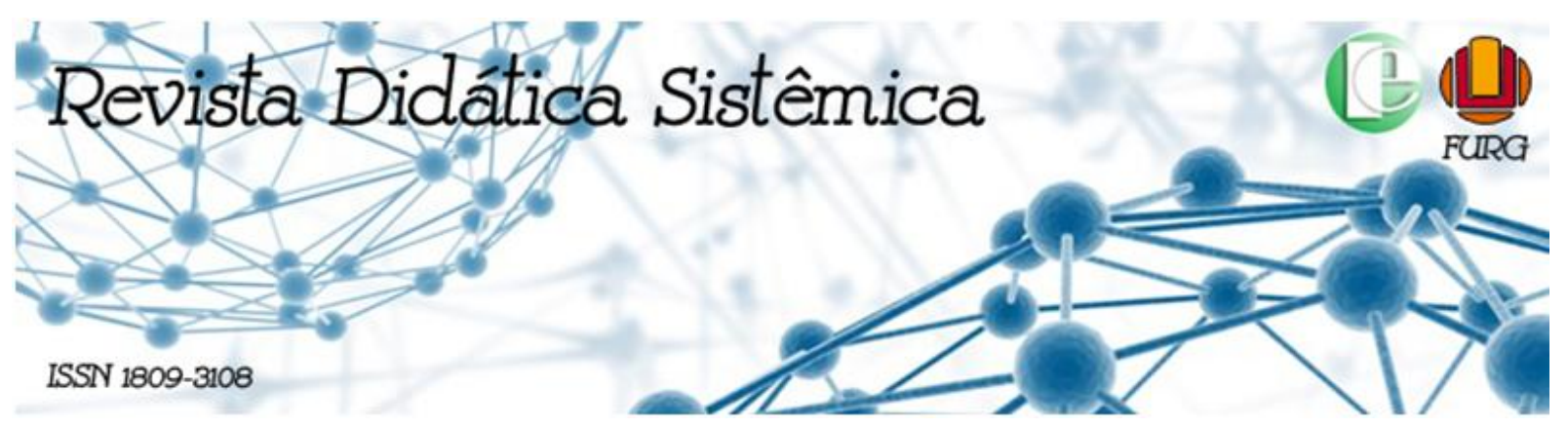

\title{
O IMPACTO DO PIBID UFRGS - EDUCAÇÃO FÍSICA/ANOS INICIAIS NA APTIDÃO FÍSICA EM ESCOLARES
}

\author{
Jacson Severo de Oliveira* \\ Lisiane Torres* \\ Mauro Castro Ignácio ${ }^{* * *}$
}

\begin{abstract}
RESUMO
Tem o objetivo de verificar o impacto de aulas de educação física escolar, desenvolvidas no projeto PIBID, na aptidão física relacionada à saúde e ao esporte, comparando níveis pré e pós-teste das crianças do $5^{\circ}$ ano do EF. É um estudo avaliativo-somativo, delineamento descritivo-quantitativo. Para a coleta dos dados, foi utilizado o PROESP-BR. Os resultados indicam melhora nos índices IMC e flexibilidade, assim como na aptidão física relacionada ao esporte. É possível constatar que as atividades realizadas no projeto tiveram um impacto positivo nas variáveis relacionadas ao esporte, flexibilidade e composição corporal. Porém, são necessários ajustes nas atividades para contemplar as demais capacidades.
\end{abstract}

Palavras-chave: aptidão física, educação física, saúde, ensino fundamental, pibid.

\section{THE IMPACT OF PIBID UFRGS - PHYSICAL EDUCATION/EARLY YEARS ON PHYSICAL FITNESS IN SCHOOLS}

\begin{abstract}
The objective of this study was to verify the impact of school physical education classes developed in the PIBID project on physical fitness related to health and sport in fifth year EF students. It is an evaluative-summative, quantitative-delineation. For the data collection, PROESP-BR was used. The results indicate improvement in BMI indexes and flexibility, as well as sport-related fitness. It is possible to verify that the activities carried out in the project had a positive impact on the several variables, being possible adjustments in the activities to contemplate the other capacities.
\end{abstract}

Keywords: physical fitness, physical education, health, elementary school, pibid.

\footnotetext{
* Bacharel e Licenciado em Educação Física pela Universidade Federal do Rio Grande do Sul (UFRGS)

** Bacharel e Licenciado em Educação Física pela Universidade Federal do Rio Grande do Sul (1989). Mestre em Ciências do Movimento Humano pela Universidade Federal do Rio Grande do Sul (1998). Doutora em Ciências do Movimento Humano pela Universidade Federal do Rio Grande do Sul (2003). Professora adjunta da Universidade Federal do Rio Grande do Sul. Foi Coordenadora do Curso de Educação Física da UFRGS nos períodos de 2008-2009 e 2010-2012. Coordenou o Núcleo Docente Estruturante do Curso de Educação Física da UFRGS no período de 2012-2014. Atuou como coordenadora de área no PIBID/UFRGS no período de julho de 2012 a março de 2016. Tem experiência na área de Educação Física Escolar, atuando, principalmente, nos seguintes temas: aptidão física em escolares, educação física escolar, desporto escolar e educação física na Educação infantil.

**** Bacharel e Licenciado em Educação Física pela Universidade Federal do Rio Grande do Sul (UFRGS). Mestrando em Ciências do Movimento Humano pela mesma instituição (PPGCMH-UFRGS).
} 


\section{EL IMPACTO DEL PIBID UFRGS - EDUCACIÓN FÍSICA/AÑOS INICIALES EN LA APTITUD FÍSICA EN LOS ESTUDIANTES}

\section{RESUMEN}

Su objetivo es verificar el impacto de las clases de educación física escolar, desarrolladas en el proyecto PIBID, en la aptitud física relacionada con la salud y el deporte, comparando los niveles de niños antes y después de la prueba en el quinto año de educación física. Es un estudio evaluativo-sumativo, diseño descriptivo-cuantitativo. Para la recolección de datos, se usó PROESP-BR. Los resultados indican una mejora en el índice de masa corporal y los índices de flexibilidad, así como en la aptitud física relacionada con el deporte. Se puede observar que las actividades realizadas en el proyecto tuvieron un impacto positivo en variables relacionadas con el deporte, la flexibilidad y la composición corporal. Sin embargo, los ajustes en las actividades son necesarios para contemplar las otras capacidades.

Palabras clave: aptitud física, educación física, salud, educación primaria, pibid.

\section{INTRODUÇÃO}

As transformações da sociedade, principalmente em relação à utilização de novas tecnologias, vêm causando mudanças de hábitos da população. Essas alterações, aliadas à falta de prática de atividades físicas sistematizadas pelas pessoas, acabam promovendo distúrbios relacionados à saúde. Atividades físicas praticadas regularmente e com orientação são importantes instrumentos para a promoção da saúde na medida em que tornam possível a manutenção de indicadores apropriados relacionados à aptidão física e podem colaborar na prevenção de diversas doenças como diabetes, obesidade, doenças cardiovasculares, entre outras (NAHAS, 2001; GLANER, 2005; STODDEN, 2014).

As ideias de Krebs e Macedo (2005) indicam que aptidão física é a composição entre padrões individuais e a habilidade de exercer diversas atividades físicas, possuindo subsídios qualitativos, oscilações entre as particularidades dos indivíduos e as distintas fases do ciclo da vida. Sendo assim, os autores sinalizam a aptidão física como a união entre características particulares de qualquer pessoa com a sua destreza no movimento, respeitando e considerando os aspectos ambientais e as experiências motoras que cada indivíduo vivencia nas diferentes fases da vida como a infância, a juventude, a vida adulta e a terceira idade.

Para Mcgee e colaboradores (2006), o aprendizado e a execução de atividades físicas durante a infância poderão propiciar, além do interesse e gosto pela prática de exercícios físicos na vida adulta, a condição favorável nos níveis de aptidão física e saúde.

Gallahue e Ozmun (2005) indicam que hábitos de vida sedentários em crianças e adolescentes podem ser causados, principalmente, pelos seguintes atributos: a utilização 
exagerada da tecnologia e a violência das ruas que pode gerar grande insegurança para práticas de brincadeiras e atividades em praças, parques, campos. Esse cenário indica, portanto, a relevância da escola enquanto espaço para a realização de práticas corporais na infância e adolescência.

Diversos autores defendem a ideia de que professores dos anos iniciais de escolarização devem ter a preocupação em propiciar aos estudantes níveis adequados de desenvolvimento das habilidades motoras, uma vez que, nesse período da escolarização, deve ser construída uma base sólida para todas as aprendizagens de práticas corporais futuras (GALLAHUE E OZMUN, 2005; SEIBEL, CARDOSO, IGNACIO, 2017).

Um bom nível de desenvolvimento motor é uma questão essencial no conjunto de qualidades motoras das crianças. Sendo assim, a inatividade ou a redução de práticas que propiciem essa situação poderão provocar consequências diretas aos envolvidos, ocasionando um impacto negativo sobre a aptidão física, restringindo, portanto, as possibilidades para desenvolver uma competência motora (BOUFFARD et al. 1996; HANDS; LARKIN, 2006). Em relação à possível associação entre a aptidão física e desenvolvimento motor, Fisher e colaboradores (2005) e Haga (2008) sugerem que as habilidades motoras fundamentais e a prática de atividades que estimulem as variáveis que compõem a aptidão física possuem vinculação, ou seja, indivíduos com boa competência motora tendem a ser ativos fisicamente, com bons níveis de aptidão física.

A aptidão física deve ser vislumbrada como um alicerce capaz de transformar estilos de vida futuros (RODRIGUES, BEZERRA, SARAIVA., 2005). Além disso, Marshal e Bouffard (1997) reforçam que, quanto maior o período de práticas que envolvam as habilidades motoras, maiores serão as probabilidades de se otimizar o repertório motor das crianças, criando possibilidades que estimulem uma pré-disposição por parte delas a participações em diversas práticas corporais.

Segundo Gaya (1989), um dos objetivos da educação física escolar é inserir o aluno no âmbito da cultura corporal do movimento humano; que se manifesta através dos jogos, danças, lutas, ginástica; atribuindo a elas um significado para a educação na promoção da saúde, do lazer, do esporte e da corporalidade.

É neste contexto que o presente estudo foi realizado, tendo como objetivo verificar o impacto das aulas de educação física escolar, desenvolvidas pelos bolsistas do PIBID/UFRGS - Subprojeto Educação Física nos Anos Iniciais do Ensino Fundamental, na aptidão física relacionada à saúde e ao esporte, dos alunos do $5^{\circ}$ ano do Ensino 
Fundamental, em escola situada na cidade de Porto Alegre - RS e comparar níveis pré e pós-teste de aptidão física relacionada à saúde e ao esporte. Os resultados obtidos neste trabalho possibilitarão não só um aprofundamento das discussões pedagógicas realizadas no PIBID / UFRGS - Subprojeto Educação Física nos Anos Iniciais do Ensino Fundamental, bem como adequações nos planejamentos de ensino do referido subprojeto.

\section{METODOLOGIA}

\subsection{Contexto da Educação Física na escola}

Na Escola, as aulas de Educação Física, antes do PIBID/UFRGS - Educação Física/Anos Iniciais -, eram ministradas pelas professoras Unidocentes. De acordo com essas professoras, em horários determinados pela Direção da Escola em dois dias da semana, com o tempo de trinta minutos, cada turma realizava no pátio algumas brincadeiras. Na maioria das vezes, as professoras disponibilizavam materiais (geralmente bola para os meninos e corda para as meninas) e ficavam administrando os conflitos que surgiam entre os alunos. Não havia planejamento para esses momentos de "aula".

Quando a Direção da Escola solicitou à Coordenadoria das Licenciaturas/UFRGS que o PIBID/UFRGS - Educação Física /Anos Iniciais desenvolvesse atividades na referida escola, a coordenadora do subprojeto, prof ${ }^{a}$. Lisiane Torres, participou de uma reunião com as professoras unidocentes e Direção da Escola e apresentou a Plano de Trabalho do referido subprojeto.

As professoras unidocentes e Direção aprovaram o Plano de Trabalho apresentado e ficou acordado que cada turma teria Educação Física em dois dias da semana e cada aula teria a duração de trinta e cinco minutos. Num dos dias da semana, os bolsistas do PIBID ministrariam a aula de Educação Física, acompanhados pela professora unidocente. No outro dia da semana, a prof ${ }^{\mathrm{a}}$. unidocente ministraria a aula, dando continuidade às atividades desenvolvidas pelo bolsista. Pretendia-se, com isso, que as professoras unidocentes aprimorassem seus conhecimentos referentes à educação física nos anos fundamentais do ensino fundamental. 


\subsection{Delimitação da pesquisa}

A população utilizada para o estudo foi de dezoito (18) alunos que constituíam o quadro do $5^{\circ}$ ano do curso de ensino fundamental, anos iniciais, do turno tarde, de uma escola estadual de Ensino Fundamental, localizada na cidade de Porto Alegre, Rio Grande do Sul. A turma formada por alunos com idade entre 10 e 12 anos foi contemplada com aulas de educação física ministradas pelos bolsistas do projeto PIBID e possuía dois (2) períodos semanais de educação física. O campo populacional escolhido se deveu ao fato da facilidade de acesso com relação aos observados, já que houve a necessidade de aplicação de testes aos envolvidos pelo autor desse estudo que foi um dos bolsistas do projeto.

\subsection{Delineamento da pesquisa}

O estudo teve seu delineamento descritivo quantitativo e, para isso, utilizou a técnica de probabilidade relativa (dimensão do efeito), em que através do processo de valoração, é definido o percentual de $30 \%$ de incremento dos índices iniciais. Diante disso, se constituiu de três fases: pré-teste (para coleta de dados na fase inicial do projeto PIBID), aulas de educação física (ministrada pelos bolsistas do projeto PIBID e pela professora regente) e pós-teste (para coleta de dados na fase final do projeto PIBID). $\mathrm{Na}$ fase pré e pós-teste, os escolares que formavam a população foram submetidos ao sistema de medidas e testes do PROESP-BR.

\subsection{Variáveis}

Os dados coletados constituíram a variável independente e foram os seguintes: medidas corporais, através da massa corporal total, estatura, envergadura e IMC (Índice de Massa Corporal); flexibilidade, por meio do teste sentar e alcançar sem o banco; força-resistência abdominal, por meio do teste Sit Up em 1 minuto; força explosiva de membros inferiores, por meio do salto horizontal; força explosiva de membros superiores, por meio do arremesso de Medicineball; agilidade, por meio do teste do quadrado; velocidade, através da corrida de vinte (20) metros; e resistência geral, por meio da corrida de seis (6) minutos. 


\subsection{Coleta de dados}

O instrumento para coleta de dados a partir de aplicação de uma bateria de testes foi o PROESP-BR.

Para a execução dos testes e medidas, os dezoito (18) escolares foram divididos em 3 grupos: um grupo com sete (7) meninos e dois grupos de meninas (um com 5 e outro com 6). A coleta de dados foi iniciada com as medidas e os testes de sala de aula; depois, foram realizados os testes de quadra, na sequencia indicada no Manual de Aplicação de Medidas e Testes, Normas e Critérios de Avaliação do PROESP-BR.

A bateria de testes do PROESP-BR é composta das seguintes medidas e testes: medida da massa corporal (peso), medida da estatura (altura), medida de envergadura, teste de flexibilidade (sentar e alcançar), medida do índice de massa corporal (IMC), teste de resistência abdominal (Sit Up), teste de aptidão cardiorrespiratória (corrida/caminhada dos 6 minutos), teste de força explosiva de membros superiores (arremesso do medicineball), teste de força explosiva de membros inferiores (salto horizontal), teste de agilidade (teste do quadrado) e teste de velocidade de deslocamento (corrida de 20 metros).

A partir da produção de um plano de trabalho, que contemplava as três unidades trabalhadas durante o período letivo, foram planejadas as aulas de educação física para uma turma de $5^{\circ}$ ano do ensino fundamental da escola. A estrutura dessas aulas estabelecia um momento de aquecimento (parte inicial), de desenvolvimento (parte principal) e um de volta à calma (parte final) para serem ministrados. O objetivo principal do plano de trabalho era proporcionar o desenvolvimento das habilidades motoras fundamentais e das capacidades físicas que compõem o grupo de aptidão física relacionada à saúde e ao esporte. Diante do estabelecido, as aulas foram desenvolvidas através de estafetas, circuitos, sequências de movimentos, jogos situacionais, minijogos e atividades gímnicas, considerando os diferentes contextos de cada aluno e contemplando o caráter lúdico das atividades.

Após o período de vinte (20) semanas de prática de educação física na escola, os escolares foram reavaliados através da mesma bateria de testes e medidas, inclusive mantendo as ordens de execuções. 


\subsection{Análise de dados}

Os dados coletados, tanto na fase pré-teste e pós-teste do único grupo, foram classificados de acordo com os critérios estabelecidos pelo PROESP-BR. Além disso, os mesmos dados coletados foram analisados com o intuito de verificar se os índices melhoraram ou pioraram após a realização das aulas de Educação Física.

\subsection{Procedimentos éticos}

No Plano de Trabalho do PIBID/UFRGS - Educação Física - Anos Iniciais -, apresentado às professoras e à Direção da Escola e aprovado pelas mesmas, constava como uma das atividades a ser desenvolvida à avaliação da aptidão física relacionada à saúde e ao esporte dos alunos dos anos iniciais do ensino fundamental em dois momentos: no início e ao final do ano letivo. O Manual de Aplicação dos Testes e Medidas do PROESP foi anexado ao Plano de Trabalho.

Na reunião de País, foi explicada a Bateria de Testes e Medidas que seria utilizada e os pais/responsáveis foram solicitados a comunicar às professoras se havia alguma restrição/não autorização do aluno em realizar algum teste/medida. Em cada dia da realização dos testes, foi perguntado a cada aluno se queria realizar ou não as medidas e testes e a decisão do aluno foi sempre respeitada.

A pesquisa faz parte de um projeto maior, aprovado pelo comitê de ética da UFRGS, de número 259.883.

\section{APRESENTAÇÃO E DISCUSSÃO DOS RESULTADOS}

Os resultados apresentados a seguir foram organizados tendo como referência os pontos de corte adotados no PROESP-BR.

\subsection{Sobre a aptidão física relacionada à saúde}

Como podemos observar na Tabela 1, os 8 alunos que já estavam na zona saudável no pré-teste permaneceram na zona saudável no pós-teste. Observa-se, ainda, que 7 alunos revelaram melhoras nos índices de IMC na segunda avaliação. Em relação 
aos 3 alunos que já estavam na zona de risco e permaneceram nesta no pós-teste, observou-se que seus índices, na segunda avaliação, foram piores em relação à primeira. Nesta variável, observa-se que 71,4\% dos estudantes melhoraram seus índices, sendo que 3 deles saíram da zona de risco e ingressaram na zona saudável. Quatro alunos realizaram apenas a uma fase de teste, ou a pré-teste ou pós-teste, não sendo possível estabelecer a comparação.

Tabela 1 - Resultados Índice de Massa Corporal (IMC)

\begin{tabular}{c|cc|cc}
\hline Estudante & \multicolumn{2}{|c|}{$\begin{array}{c}\text { Pré-teste } \\
\text { Valor / Classificação }\end{array}$} & \multicolumn{2}{c}{$\begin{array}{c}\text { Pós-teste } \\
\text { Valor / Classificação }\end{array}$} \\
\hline Aluno 1 & 16,17 & z.saudável & 15,73 & z.saudável \\
Aluno 2 & 30,49 & z.risco & 32,02 & z.risco \\
Aluno 3 & 18 & z.saudável & & \\
Aluno 4 & 21,3 & z.risco & 19,23 & z.saudável \\
Aluno 5 & 16,63 & z.saudável & 16,6 & z.saudável \\
Aluno 6 & 13,77 & z.saudável & 13,32 & z.saudável \\
Aluno 7 & 31,47 & z.risco & 33,33 & z.risco \\
Aluno 8 & 20,88 & z.risco & 19,9 & z.saudável \\
Aluno 9 & 27,84 & z.risco & 30,47 & z.risco \\
Aluno 10 & & & 20,08 & z.saudável \\
Aluno 11 & 21,26 & z.risco & 20,72 & z.saudável \\
Aluno 12 & & & 17,07 & z.saudável \\
Aluno 13 & 16,66 & z.saudável & 15,56 & z.saudável \\
Aluno 14 & 19,78 & z.saudável & 18,55 & z.saudável \\
Aluno 15 & 19,21 & z.saudável & 18,66 & z.saudável \\
Aluno 16 & 15,24 & z.saudável & & \\
Aluno 17 & 20,67 & z.saudável & 20,48 & z.saudável \\
Aluno 18 & 14,6 & z.saudável & 14,49 & z.saudável \\
\hline
\end{tabular}

Fonte: Elaboração Própria

Sobre a variável flexibilidade, 4 alunos, no pós teste, alteraram sua classificação: 3 alunos passaram da zona de risco para a zona saudável e um aluno ingressou na zona de risco. Houve avanços, também, em 7 alunos que tiveram índices maiores em relação à comparação do pós-teste ao pré-teste e permaneceram na zona saudável. Apenas um aluno não teve alterações de resultado entre a fase pré e pós-teste nesta variável, e 2 alunos pioraram seus índices. Nesta variável, observa-se que $71,4 \%$ dos estudantes melhoraram seus índices. Da mesma forma que a variável anterior, também 4 alunos realizaram apenas uma das fases de teste. 
Tabela 2 - Resultados do Teste sentar e alcançar sem banco

\begin{tabular}{c|cc|cc}
\hline Estudante & \multicolumn{2}{|c|}{$\begin{array}{c}\text { Pré-teste } \\
\text { Valor / Classificação }\end{array}$} & \multicolumn{2}{c}{$\begin{array}{c}\text { Pós-teste } \\
\text { Valor / Classificação }\end{array}$} \\
\hline Aluno 1 & 31 & z.saudável & 22 & z.risco \\
Aluno 2 & 27 & z.risco & 25 & z.risco \\
Aluno 3 & 27 & z.risco & & z.risco \\
Aluno 4 & 33 & z.risco & 35 & z.saudável \\
Aluno 5 & 40 & z.saudável & 40 & z.saudável \\
Aluno 6 & 36 & z.risco & 37 & z.saudável \\
Aluno 7 & 33 & z.saudável & 40 & z.saudável \\
Aluno 8 & 31 & z.saudável & 34 & z.saudável \\
\hline Aluno 9 & 36 & z.risco & 39 & z.saudável \\
Aluno 10 & & & 50 & z.saudável \\
Aluno 11 & 38 & z.saudável & 41 & z.risco \\
Aluno 12 & & & 14 & z.saudável \\
Aluno 13 & 48 & z.saudável & 50 & z.saudável \\
Aluno 14 & 43 & z.saudável & 49 & z.saudável \\
Aluno 15 & 34 & z.risco & 40 & z.risco \\
\hline Aluno 16 & 41 & z.saudável & & z.risco \\
Aluno 17 & 21 & z.risco & 29 & 27 \\
Aluno 18 & 29 & z.risco & & \\
\hline
\end{tabular}

Fonte: Elaboração Própria

No que se refere à capacidade força-resistência muscular avaliada através da resistência abdominal (Sit Up), não houve estudantes que, no pré-teste, estavam na zona de risco e, no pós-teste, estavam na zona saudável. Observou-se, apenas, 3 estudantes que estavam, no pré-teste, na zona saudável e elevaram um pouco seus índices no pós-teste. Nessa variável, considera-se preocupante o fato de 4 estudantes que, no pré-teste, estavam na zona saudável e no pós-teste ingressaram na zona de risco, assim como 7 estudantes que ainda permaneceram na zona de risco no pós-teste, apresentando regressão nos seus índices. Não foi possível determinar a melhora ou piora dos índices de 4 escolares, já que realizaram apenas uma fase de testes. Nessa variável, portanto não foi observado efeito positivo decorrente das aulas de educação física. 
Tabela 3 - Resultados do Teste resistência abdominal (Sit Up)

\begin{tabular}{|c|c|c|c|c|}
\hline Estudante & \multicolumn{2}{|c|}{$\begin{array}{c}\text { Pré-teste } \\
\text { Valor / Classificação }\end{array}$} & \multicolumn{2}{|c|}{$\begin{array}{c}\text { Pós-teste } \\
\text { Valor / Classificação }\end{array}$} \\
\hline Aluno 1 & 41 & z.saudável & 39 & z.risco \\
\hline Aluno 2 & 12 & Z.risco & 11 & Z.risco \\
\hline Aluno 3 & 20 & Z.risco & & \\
\hline Aluno 4 & 27 & z.saudável & 16 & z.risco \\
\hline Aluno 5 & 24 & Z.risco & 20 & Z.risco \\
\hline Aluno 6 & 26 & z.saudável & 22 & z.risco \\
\hline Aluno 7 & 22 & z.risco & 7 & z.risco \\
\hline Aluno 8 & 28 & Z.risco & 26 & Z.risco \\
\hline Aluno 9 & 21 & z.risco & 20 & z.risco \\
\hline Aluno 10 & & & 26 & z.risco \\
\hline Aluno 11 & 27 & z.saudável & 25 & z.risco \\
\hline Aluno 12 & & & 34 & z.risco \\
\hline Aluno 13 & 30 & z.saudável & 34 & z.saudável \\
\hline Aluno 14 & 33 & z.saudável & 34 & z.saudável \\
\hline Aluno 15 & 22 & z.risco & 23 & z.risco \\
\hline Aluno 16 & 31 & z.saudável & & \\
\hline Aluno 17 & 21 & z.risco & 9 & z.risco \\
\hline Aluno 18 & 25 & z.risco & 22 & z.risco \\
\hline
\end{tabular}

Fonte: Elaboração Própria

Em relação aos índices encontrados para a variável de resistência cardiorrespiratória, apenas 8 escolares realizaram o pré e pós-teste. Dentre estes, um estudante que estava inicialmente na zona saudável, passou para a zona de risco. E, ainda, 3 estudantes melhoraram seus índices sem alterar sua classificação, além de 4 estudantes permanecerem na zona de risco e piorarem seus índices.

Tabela 4 - Resultados do Teste aptidão cardiorrespiratória

\begin{tabular}{c|cc|cc}
\hline \multirow{2}{*}{ Estudante } & \multicolumn{2}{c}{$\begin{array}{c}\text { Pré-teste } \\
\text { Valor / Classificação }\end{array}$} & \multicolumn{2}{c}{$\begin{array}{c}\text { Pós-teste } \\
\text { Valor / Classificação }\end{array}$} \\
\hline Aluno 1 & 1078 & z.saudável & 963 & \\
Aluno 2 & 714 & z.risco & \\
Aluno 3 & 756 & z.risco & \\
Aluno 4 & 668 & z.risco & 748 & z.risco \\
Aluno 5 & 801 & z.risco & 810 & z.risco \\
Aluno 6 & 801 & z.saudável & 652 & z.risco \\
Aluno 7 & 619 & z.risco & 621 &
\end{tabular}




\begin{tabular}{c|cc|cc}
\hline Estudante & \multicolumn{2}{|c|}{$\begin{array}{c}\text { Pré-teste } \\
\text { Valor / Classificação }\end{array}$} & $\begin{array}{c}\text { Pós-teste } \\
\text { Valor / Classificação }\end{array}$ \\
\hline Aluno 10 & & & & \\
Aluno 11 & 756 & z.risco & 882 & z.risco \\
Aluno 12 & & & & \\
Aluno 13 & 837 & z.saudável & & z.risco \\
Aluno 14 & 846 & z.saudável & 748 & z.risco \\
Aluno 15 & 784 & z.risco & & z.saudável \\
Aluno 16 & 887 & z.saudável & 735 & z.risco \\
Aluno 17 & 756 & z.saudável & 1242 & \\
Aluno 18 & 1220 & & &
\end{tabular}

Fonte: Elaboração Própria

A análise dos dados coletados relativos às variáveis pertencentes ao grupo da aptidão física relacionada à saúde evidencia que as aulas de educação física promovidas pelos bolsistas do PIBID/UFRGS - Educação Física/Anos Iniciais não foram desenvolvidas de forma a provocar um efeito positivo nessas variáveis. Embora tenha sido observada uma alteração positiva nos índices referentes ao IMC e à flexibilidade, grande parte dos indivíduos não melhorou seu desempenho nas zonas de classificação em relação à resistência cardiorrespiratória e à força/resistência muscular.

Resultados similares são encontrados no trabalho de Pelegrini e colaboradores (2011), após a análise da aptidão física de 7507 escolares brasileiros, entre 7 e 10 anos de idade, sendo constatado o baixo nível de aptidão física dos escolares, apresentando risco à saúde para flexibilidade $(58,3 \%$ em meninos, $51,2 \%$ em meninas), para força/resistência muscular (75,3\% em meninos, 73,8\% em meninas) e para aptidão cardiorrespiratória (80,8\% em meninos, $77,6 \%$ em meninas).

Os dados encontrados para a aptidão física relacionada à saúde também corroboram aos de outro estudo, proposto por Guedes e Guedes (2001), que tinha por objetivo desenvolver a análise quanto à intensidade, à duração e à frequência dos esforços físicos a que são submetidos os escolares de 15 escolas municipais, localizadas em Londrina, no Paraná, em 144 aulas de educação física escolar. Os principais resultados encontrados sinalizam que o nível de intensidade e a duração dos esforços físicos promovidos aos escolares foram insuficientes para determinar benefícios à saúde, pois foram ofertadas poucas oportunidades de os escolares participarem de esforços físicos de moderada à elevada intensidade por períodos adequados. 
Especificamente se tratando da variável de força/resistência abdominal, Serassuelo e colaboradores (2005) encontraram, em seus estudos, que $80 \%$ dos escolares, com média de idade entre 11 e 12 anos, apareciam abaixo dos níveis mínimos desejáveis para esta faixa etária. Sobre a variável flexibilidade, são preocupantes os resultados encontrados no estudo de Burgos e colaboradores (2012), com escolares entre 7 e 17 anos de idade, em Santa Cruz do Sul/RS, que apresenta um índice de $72 \%$ de meninos e de $67,2 \%$ de meninas abaixo dos níveis estipulados pelo PROESP-BR.

\subsection{Sobre a aptidão física relacionada ao esporte}

No que se refere à força explosiva de membros superiores, dentre os 14 alunos avaliados, 7 incrementaram seus índices e trocaram de classificação (50\%). Outros 5 estudantes melhoraram seus índices e permaneceram nas mesmas categorias do pré-teste. Além disso, 2 escolares permaneceram nas mesmas categorias do pré-teste, apesar de apresentar regressão em seus índices. Ainda houve 4 escolares que não realizaram uma das fases de avaliação.

A tabela a seguir ilustra os resultados obtidos em relação à variável força-explosiva de membros inferiores. Dentre os 14 alunos avaliados, 6 melhoraram seus índices e trocaram de classificação $(42,8 \%)$, enquanto 8 permaneceram na mesma categoria. Importante ressaltar que não houve regressão nos índices dos alunos no pós-teste em relação ao pré-teste. Em 4 alunos, não foi possível estabelecer o comparativo entre fases pela não execução de alguma delas.

Tabela 5 - Resultados do Teste força explosiva de membros inferiores

\begin{tabular}{c|cc|cc}
\hline Estudante & \multicolumn{2}{|c|}{$\begin{array}{c}\text { Pré-teste } \\
\text { Valor / Classificação }\end{array}$} & \multicolumn{2}{c}{$\begin{array}{c}\text { Pós-teste } \\
\text { Valor / Classificação }\end{array}$} \\
\hline Aluno 1 & 127 & Fraco & 151 & Razoável \\
Aluno 2 & 113 & Fraco & 124 & Fraco \\
Aluno 3 & 98 & Fraco & & \\
Aluno 4 & 95 & Fraco & 135 & Bom \\
Aluno 5 & 100 & Fraco & 120 & Fraco \\
Aluno 6 & 135 & Bom & 144 & Bom \\
Aluno 7 & 135 & Razoável & 154 & Bom \\
Aluno 8 & 120 & Fraco & 148 & Bom \\
Aluno 9 & 115 & Fraco & 118 & Fraco \\
Aluno 10 & & & 166 & Muito bom \\
\hline
\end{tabular}




\begin{tabular}{c|cc|cc}
\hline Estudante & \multicolumn{2}{|c|}{$\begin{array}{c}\text { Pré-teste } \\
\text { Valor / Classificação }\end{array}$} & \multicolumn{2}{c}{$\begin{array}{c}\text { Pós-teste } \\
\text { Valor / Classificação }\end{array}$} \\
\hline Aluno 11 & 130 & Razoável & 132 & Razoável \\
Aluno 12 & & & 158 & Fraco \\
Aluno 13 & 141 & Bom & 153 & Muito bom \\
Aluno 14 & 159 & Muito bom & 160 & Muito bom \\
Aluno 15 & 122 & Fraco & 144 & Bom \\
Aluno 16 & 100 & Fraco & & Fraco \\
Aluno 17 & 103 & Fraco & 121 & Bom \\
Aluno 18 & 155 & Bom & 157 & \\
\hline
\end{tabular}

Fonte: Elaboração Própria

Os resultados a seguir, apresentados na tabela 7, são referes à variável agilidade. Dos 14 alunos avaliados, 10 melhoraram seus índices e trocaram de categoria, totalizando $71,4 \%$. Outros 4 escolares permaneceram na mesma classificação embora tenham melhorado seus índices. Destaca-se o fato de que nenhum aluno apresentou rendimento pior no pós-teste. Assim como nas variáveis anteriores, de 18 alunos, 4 deles não participaram de alguma das fases previstas.

Tabela 6 - Resultados do Teste de agilidade

\begin{tabular}{|c|c|c|c|c|}
\hline \multirow{2}{*}{$\begin{array}{c}\text { Estudante } \\
\text { Aluno } 1\end{array}$} & \multicolumn{2}{|c|}{$\begin{array}{c}\text { Pré-teste } \\
\text { Valor / Classificação }\end{array}$} & \multicolumn{2}{|c|}{$\begin{array}{c}\text { Pós-teste } \\
\text { Valor / Classificação }\end{array}$} \\
\hline & 6,75 & Razoável & 5,75 & Muito bom \\
\hline Aluno 2 & 6,91 & Razoável & 6,66 & Bom \\
\hline Aluno 3 & 6,59 & Razoável & & \\
\hline Aluno 4 & 7,13 & Razoável & 6,63 & Bom \\
\hline Aluno 5 & 7,37 & Fraco & 6,84 & Razoável \\
\hline Aluno 6 & 6,16 & Muito bom & 5,81 & Excelência \\
\hline Aluno 7 & 7,03 & Fraco & 6,37 & Bom \\
\hline Aluno 8 & 6,66 & Bom & 6,37 & Bom \\
\hline Aluno 9 & 6,22 & Bom & 5,68 & Muito bom \\
\hline Aluno 10 & & & 5,75 & Muito bom \\
\hline Aluno 11 & 7,19 & Razoável & 6,1 & Muito bom \\
\hline Aluno 12 & & & 5,97 & Bom \\
\hline Aluno 13 & 6,53 & Muito bom & 5,81 & Muito bom \\
\hline Aluno 14 & 6,35 & Muito bom & 6,31 & Muito bom \\
\hline Aluno 15 & 7,09 & Razoável & 6,5 & Muito bom \\
\hline Aluno 16 & 5,82 & Excelência & & \\
\hline Aluno 17 & 7,15 & Razoável & 6,56 & Bom \\
\hline Aluno 18 & 5,97 & Muito bom & 5,66 & Muito bom \\
\hline
\end{tabular}

Fonte: Elaboração Própria 
Em relação à variável velocidade, observou-se que 5 estudantes melhoraram seus índices e trocaram de categoria (35,7\%), enquanto 4, mesmo apresentando melhora dos seus índices, permaneceram na mesma categoria. Outros 5 estudantes apresentaram rendimento pior no pós-teste em relação ao pré-teste. A quantidade de 4 alunos que realizou apenas uma das fases de teste permaneceu nesta variável.

Tabela 7 - Resultados do Teste de velocidade de deslocamento

\begin{tabular}{|c|c|c|c|c|}
\hline \multirow{2}{*}{$\begin{array}{c}\text { Estudante } \\
\text { Aluno } 1\end{array}$} & \multicolumn{2}{|c|}{$\begin{array}{c}\text { Pré-teste } \\
\text { Valor / Classificação }\end{array}$} & \multicolumn{2}{|c|}{$\begin{array}{c}\text { Pós-teste } \\
\text { Valor / Classificação }\end{array}$} \\
\hline & 3,5 & Muito bom & 3,31 & Muito bom \\
\hline Aluno 2 & 3,94 & Bom & 4,22 & Razoável \\
\hline Aluno 3 & 3,75 & Razoável & & \\
\hline Aluno 4 & 4,03 & Bom & 4,13 & Bom \\
\hline Aluno 5 & 4,34 & Fraco & 4,15 & Fraco \\
\hline Aluno 6 & 3,68 & Muito bom & 3,75 & Muito bom \\
\hline Aluno 7 & 4,65 & Fraco & 4,06 & Fraco \\
\hline Aluno 8 & 4,09 & Razoável & 3,75 & Bom \\
\hline Aluno 9 & 3,68 & Muito bom & 3,91 & Bom \\
\hline Aluno 10 & & & 3,69 & Muito bom \\
\hline Aluno 11 & 4,16 & Bom & 4,12 & Razoável \\
\hline Aluno 12 & & & 3,62 & Razoável \\
\hline Aluno 13 & 3,62 & Muito bom & 3,56 & Muito bom \\
\hline Aluno 14 & 4,22 & Razoável & 3,53 & Muito bom \\
\hline Aluno 15 & 4,19 & Razoável & 4 & Bom \\
\hline Aluno 16 & 3,53 & Muito bom & & \\
\hline Aluno 17 & 4,75 & Fraco & 4,31 & Razoável \\
\hline Aluno 18 & 3,72 & Bom & 3,56 & Muito bom \\
\hline
\end{tabular}

Fonte: Elaboração Própria

Estima-se que as aulas de educação física ministradas pelos bolsistas do PIBID/UFRGS Educação Física/Anos Iniciais, cujo planejamento envolvia práticas corporais diversificadas e sistematizadas, tenham provocado um efeito considerável no que se refere à aptidão física relacionada ao esporte.

Observa-se que esses dados corroboram com as idéias de Bouffard (1996) e Marshall e Bouffard(1997), pois, quanto maior número de experiências que explorem as habilidades motoras, o movimento, mais qualidade do repertório motor a criança poderá adquirir, gerando uma propensão à participação em diferentes práticas corporais. Corroborando com as evidências indicadas nesse estudo, uma pesquisa produzida por Guedes e Barbanti (1995) avaliou a capacidade de potência em crianças e adolescentes, 
apresentando uma progressão linear em indivíduos com a faixa etária próxima à idade dos escolares que fizeram parte do presente estudo.

Em síntese, no que se refere à aptidão física relacionada ao esporte, foi observado um aumento considerável no rendimento dos estudantes em cada variável analisada: na força de membros superiores, $50 \%$ dos avaliados melhoraram sua classificação, enquanto que, na velocidade, o percentual de escolares nessa condição foi de $35,7 \%$. Em relação à força de membros inferiores e agilidade, os percentuais de estudantes que apresentaram melhores índices no pós-teste foi de $42,8 \%$ e 71,4 \%, respectivamente.

\section{CONCLUSÕES E SUGESTÕES}

Em virtude dos resultados encontrados neste estudo, é possível constatar que os valores apresentados para as capacidades da aptidão física relacionada à saúde são insuficientes para que o efeito das aulas seja conceituado positivo, ou seja, o impacto das aulas de educação física para a aptidão física relacionada à saúde de grande parte dos escolares poderia ter sido de uma condição mais favorável. Já para a aptidão física relacionada ao esporte, a grande maioria dos escolares apresentou ganhos e incrementos em todas as capacidades, determinando, assim, que as aulas foram satisfatórias nesse contexto, causando um impacto positivo.

Diversos fatores podem ter influenciado no resultado final da comparação entre os níveis pré e pós-teste do único grupo de escolares, como, por exemplo, a motivação dos alunos em realizar as atividades, o número de períodos por semana que a escola oferece para aulas de educação física, a metodologia utilizada pelos bolsistas do PIBID/UFRGS Subprojeto Educação Física nos Anos Iniciais do Ensino Fundamental, o tempo de duração de cada período, a estrutura e recursos que a escola disponibiliza para as aulas. É necessário, porém, aprimorar o desenvolvimento das atividades do referido subprojeto para que as aulas de educação física tenham um impacto mais positivo no que se refere à aptidão física relacionada à saúde e ao esporte.

Sugere-se que uma das possibilidades para se encontrar resultados mais favoráveis na aptidão física relacionada à saúde seria o Subprojeto Educação Física nos Anos Iniciais do Ensino Fundamental ser ajustado para um modelo com períodos de aula de educação física mais prolongados (ao invés de 35 minutos, passar para 45 minutos por período, totalizando 90 minutos por semana). Outro aspecto importante é que as duas aulas semanais sejam 
conduzidas pelos bolsistas do subprojeto, uma vez que foi observada a dificuldade das unidocentes em dar continuidade aos conteúdos planejados e desenvolvidos pelos bolsistas. Outra dificuldade observada nas aulas ministradas pelas unidocentes foi a gestão do tempo de aula: havia muito tempo de espera, e o tempo de prática ficava abaixo do desejado.

As alterações no desenvolvimento do PIBID/UFRGS Educação Física/Anos Iniciais são importantes, não somente para qualificar as aulas de educação física a serem desenvolvidas, oportunizar aos alunos dos anos iniciais um incremento em seus índices de aptidão física relacionada à saúde e ao esporte, mas também para os bolsistas construírem um repertório de ensino de forma a articular o ensino dos elementos da cultura corporal, com o desenvolvimento da aptidão física e dos aspectos sociocognitivos que o âmbito escolar propicia.

Considerando o problema de pesquisa levantado para este estudo (Qual o impacto de aulas de educação física escolar na aptidão física relacionada à saúde e ao esporte?), foram verificadas as seguintes situações: o impacto das aulas de educação física escolar, para boa parte dos escolares, ficou abaixo do esperado na aptidão física relacionada à saúde, pois, mesmo sendo constatada uma alteração nos níveis das variáveis IMC e flexibilidade, boa parte dos escolares não melhorou seus índices referentes à resistência cardiorrespiratória e à força/resistência muscular. Já em relação à aptidão física relacionada ao esporte, o impacto foi positivo, pois se observa um aumento considerável no rendimento dos estudantes em cada variável analisada: na força de membros superiores e velocidade, $50 \%$ dos avaliados melhoraram sua classificação, enquanto que, na força de membros inferiores e na agilidade, os percentuais de estudantes que apresentaram melhores índices no pós-teste foi de $42 \%$ e $71 \%$, respectivamente.

A importância dos resultados obtidos impõe uma reflexão sobre a relevância do estudo e propicia qualificar, com maiores subsídios, alternativas para o aprimoramento do Programa Institucional de Bolsa de Iniciação à Docência - PIBID/UFRGS - Educação Física nos Anos Iniciais. Algumas alterações poderão ser realizadas para aprimorar os índices de cada capacidade física trabalhada. Portanto, torna-se visivelmente importante a função do professor de educação física, sendo essencial para que a criança possa adquirir hábitos que influenciem positivamente na promoção da saúde, do lazer, e na melhoria do repertório motor quando adulto. 


\section{REFERÊNCIAS}

BOUFFARD, M. et al. A test of the activity deficit hypothesis with children with movement difficulties. Adapted Physical Activity Quartely, v. 13, p. 61-73, 1996.

BURGOS M., REUTER C., TORNQUIST L., PICCIN A., RECKZIEGEL M., POHL H., BURGOS L. Perfil de aptidão física relacionada à saúde de crianças e adolescentes de 7 a 17 anos. Journal of the Health Sciences Institute, v. 30, n. 2, p. 171-175, 2012.

FISHER, A. et al. Fundamental movement skills and habitual physical activity in young children. Medicine, Science and Sports Exercise, v. 37, n. 4, p. 684-688, 2005.

GAYA, A.C.A. Educação Física: educação e saúde? Revista da Educação Física/UEM, Maringá.v. 1, n. 1,p. 36-38, 1989

GALLAHUE, D.L.; OZMUN, J.C. Compreendendo o desenvolvimento motor: bebês, crianças, adolescentes e adultos. 3. ed. São Paulo: Phortoe, 2005.

GLANER, M.F. Aptidão física relacionada à saúde de adolescentes rurais e urbanos em relação a critérios de referência. Revista Brasileira Educação Física e Esportes. v. 19. n. 1. 2005.

GUEDES, D.P.; GUEDES, J.E.R.P. Esforços físicos nos programas de educaçäo física escolar. Revista Paulista de Educação Física, São Paulo, v. 15, n. 1, p. 33-44, 2001.

GUEDES, D.P.; BARBANTI, V. J. Desempenho motor em crianças e adolescente. Revista Paulista de Educação Física, São Paulo, v. 9, n. 1, 1995.

HAGA, M. The relationship between physical fitness and motor competence in children. Child: care, health and development, v. 34, n. 3, p. 329-334, 2008.

HANDS, B.; LARKIN, D. Physical fitness differences in children with and without motor learning difficulties. European Journal of Special Needs Education, v. 21, p. 447-456, 2006.

KREBS, R.J.; MACEDO, F. de O. Desempenho da aptidão física de crianças e adolescentes. Revista Digital, Buenos Aires, v. 10, n. 85, jun. 2005.

MARSHALL, J.D.; BOUFFARD, M. The effects of quality daily physical education on movement competency in obese versus nonobese children. Adapted Physical Activity Quartely, v. 14, p. 222-237, 1997.

MCGEE R, WILLIAMS S, HOWDEN-CHAPMAN P, MARTIN J, KAWACHI I. Participation in clubs and groups from childhood to adolescence and its effects on attachment and self-esteem. J Adolesc, v. 29, n. 1, p. 1-17, 2006.

NAHAS, M.V. Atividade física, saúde e qualidade de vida: conceitos e sugestões para um estilo de vida ativo. 2. ed. Londrina: Midiograf, 2001.

PELEGRINI A., SILVA D., PETROSKI E., GLANER M. Aptidão física relacionada à saúde de escolares brasileiros: dados do projeto esporte Brasil. Revista Brasileira Med Esporte, v. 5, n. 2, mar./abr. 2011.

RODRIGUES L.P., BEZERRA P., SARAIVA L. Influência do meio (urbano e rural) no padrão de aptidão física de rapazes de Viana do Castelo, Portugal. Revista Portuguesa de Ciência do Desporto, v. 5, n. 1, p. 77-84, 2005.

SEIBEL, Raul de Fraga; CARDOSO, Lisiane Torres; IGNACIO, Mauro Castro. PERFIL DA APTIDÃO FÍSICA DE ESCOLARES DOS ANOS INICIAIS DO ENSINO FUNDAMENTAL DE UMA ESCOLA PUBLICA ATENDIDA PELO PROGRAMA DE INICIAÇÃO A DOCENCIA (PIBID) - EDUCAÇÃO FÍSICA. Revista Ciência e Conhecimento, São Jerônimo, v. 11, n. 1, p. 47-59, jul. 2017

SERASSUELO, J. et al. Aptidão física relacionada à saúde em escolares de baixo nível socioeconômico. Revista Brasileira de Educação Física/UEM, Maringá v. 16, p. 5-11, set. 2005.

STODDEN, David F. et al. Dynamic relationships between motor skill competence and healthrelated fitness in youth. Pediatric exercise science, v. 26, n. 3, 2014. 